\title{
Focusing and Restricting: Two Aspects of Motivational Selectivity in Adulthood
}

\author{
Michaela Riediger and Alexandra M. Freund \\ Max Planck Institute for Human Development
}

\begin{abstract}
Using a short-term longitudinal design, the authors investigated implications of 2 facets of motivational selectivity-restricting (to few goals) and focusing (on central and similar goals) - for goal-pursuit investment. Participants were 20-69 years old (Time $1, N=177$; Time $2, N=160$ ). Results show that motivational selectivity in terms of focusing (but not in terms of restricting) is associated with an enhanced involvement in goal pursuit (assessed 3 months later), irrespective of age. Structural equation models demonstrated that this association is completely mediated by the degree of mutual facilitation among goals. Furthermore, motivational selectivity increases from middle to older adulthood. This contributes to the maintenance of high goal involvement into later adulthood, despite aging-related increases in resource limitations.
\end{abstract}

Keywords: motivational selectivity, adult development, goal-pursuit involvement, intergoal facilitation

"Don't put all your eggs in one basket," or "Those who follow every path never reach any destination"-folk wisdom offers contradictory advice. Is it better to diversify and have many goals or to focus one's resources on a limited number of options? Or is it not an "either-or" question, and selectivity is advisable in some situations but not others? We propose that a person's age can be seen as a proxy variable for a group of factors determining selectivity. In this article, we present an empirical study on the development and function of two forms of motivational selectivity, restricting (to few goals) and focusing (on central and similar goals). This study tested whether people react to age-associated decreases in goal-relevant resources by becoming increasingly selective in their future-oriented motivations and whether this increase in selectivity contributes to the maintenance of high behavioral involvement in goal pursuit in a reality of increasingly limited resources.

A key feature of human evolution is the emergence of a behavioral repertoire that is both vast and flexible and thus opens a multitude of potential developmental pathways in a person's life (D. H. Ford \& Lerner, 1992). The breadth of developmental options is delimited by biological and social factors but is nevertheless immense. This is of great adaptive advantage because it

Michaela Riediger and Alexandra M. Freund, Max Planck Institute for Human Development, Berlin, Germany.

Alexandra M. Freund is now at the University of Zurich, Switzerland. We thank Dulce Erdt, Antje Rauers, Axinja Kalusche, Cornelia Wrzus, Sanja Hodzic, Poldi Kuhl, Ulrike Altmann, and Max Rotter for their help in conducting the study, and we appreciate the time and effort our participants invested in this research.

Correspondence concerning this article should be addressed to Michaela Riediger, Center for Life Span Psychology, Max Planck Institute for Human Development, Lentzeallee 94, 14195 Berlin, Germany, or Alexandra M. Freund, University of Zurich, Institute of Psychology, Applied Psychology, Universtitaetstr. 84, CH-8006, Zurich, Switzerland. E-mail: riediger@mpib-berlin.mpg.de or freund@ angpsy.unizh.ch allows flexible adjustments to different environmental conditions and demands. However, it also poses a challenge to developmental regulation. Pursuing a developmental path takes resources, such as time or energy, that are available only in limited amounts. Following a large range of different developmental paths leads to diffusion of resources that might be needed to attain or maintain high levels of functioning in a given domain. On the one hand, people therefore need to focus their resources. On the other hand, diversity is an important means for adapting to changing environmental or social demands. The challenge for developmental regulation, therefore, is to find the right balance between limiting one's potential and overextending oneself.

Regulatory processes that address this challenge occur on both the societal and the personal level (Freund, 2003; Heckhausen, 1999). Societies "canalize" individual development through age norms and age-graded opportunity structures. Opportunity structures refer to the amount of resources, support, and reinforcement society provides for the pursuit of particular developmental options at a given age (e.g., starting out a new career in younger vs. middle or older adulthood; Neugarten, Moore, \& Lowe, 1965; Settersten \& Hagestad, 1996a, 1996b). Even within this sociostructural scaffolding, however, the number of potential developmental options typically exceeds the resources available to the individual, who therefore needs to use additional regulatory processes. These processes can be subsumed under the notion of selectivity. Various recent theories have emphasized the fundamental role of selectivity for human development (e.g., Carstensen, Isaacowitz, \& Charles, 1999; Freund \& Baltes, 2000; Heckhausen, 1999). One example is the theory of selection, optimization, and compensation (SOC; e.g., Baltes \& Baltes, 1990). This theory posits that a focused investment of limited resources into a subset of developmental options is a universal process of developmental regulation that provides directionality to development and operates on different levels of analysis, in different domains of functioning, and across different phases of the life span. 


\section{Motivational Selectivity}

Our aim in this research was to address the phenomenon of selectivity as it is evident in developmental-regulatory processes on the part of the individual (Bandura, 2001; D. H. Ford, 1987; M. E. Ford \& Ford, 1987). Personal goals (mental representations of states that an individual wants to attain, maintain, or avoid in the future; Emmons, 1996) and goal-directed action play an important role in this respect, particularly in adulthood (e.g., Freund \& Baltes, 2000). We therefore focused on selectivity as it is evident in people's goals. We refer to this form of selectivity as motivational selectivity and define it as delimiting, either proactively or reactively, the range of one's personal goals. Proactive selectivity is intentionally initiated by the individual. Reactive selectivity is brought about by the individual's life circumstances. It may not require the individual's awareness or intentional initiative.

Previous research on aspects of motivational selectivity-as indexed, for example, by the concepts of elective selection (e.g., Freund \& Baltes, 2000) or life investment selectivity (e.g., Staudinger, Freund, Linden, \& Maas, 1999) — has shown that selectivity fosters an individual's subjective well-being, particularly when resources are scarce (e.g., in the case of poor health; Chou \& Chi, 2002; Staudinger \& Freund, 1998; Staudinger et al., 1999). In these studies, researchers have investigated selectivity in terms of restricting oneself to few personal goals. In the present study, we extended the notion of motivational selectivity to include, in addition to the facet of restricting (the number of goals), a second facet, namely, focusing (the content of goals). Restricting relates to the quantity of selected goals. It is characterized by selecting few (vs. many) goals. The second facet, focusing, relates to the content of selected goals. It is characterized by focusing on subjectively central (vs. marginal) and on similar (vs. diverse) goals. Central goals address life domains the person regards as highly important for his or her life satisfaction. Similar goals are comparable in the life domains they address; they focus on the same, rather than on divergent, areas of life.

Moreover, different from the aforementioned studies that have addressed the association between selectivity and psychological well-being, we targeted a more proximal outcome of selectivity in the present study, namely, goal-directed behavioral investment. Choosing goals is only a first step in eventually achieving desired outcomes. Shaping one's life course in aspired directions also requires goal-directed action. Selecting a goal, however, does not necessarily imply that the individual will also engage in behaviors directed at goal realization. Many goals remain just that: goals. We posit that the two facets of motivational selectivity-restricting (the number of goals) and focusing (the content of goals) - foster, on a behavioral level, a high involvement in goal pursuit. This should be the case because selecting few goals that address subjectively central life domains and are similar to each other might result in a high degree of mutual facilitation among the selected goals as indexed by instrumental goal relations and overlapping goal-attainment strategies (Riediger \& Freund, 2004; Wilensky, 1983). Previous research has shown that high intergoal facilitation is associated with an enhanced involvement in goal pursuit (Riediger, in press; Riediger \& Freund, 2004; Riediger, Freund, \& Baltes, 2005). However, little is known to date about characteristics that foster facilitation among goals. In the present research, we predicted that motivational selectivity (restricting and focusing) contributes to intergoal facilitation, which, in turn, leads to high involvement in goal-pursuit behaviors (see Figure 1).

\section{Age-Related Changes in Motivational Selectivity}

Taking a life span developmental perspective, we further predicted that motivational selectivity increases from early to late adulthood. This increase might accelerate beginning with the transition from middle to later adulthood. Goal-relevant resourcesthat is, means to realize aspired outcomes-are limited in all phases of life. These resource limitations become increasingly pronounced throughout life (Baltes, 1997), and particularly so in later adulthood (Baltes \& Smith, 2003; Freund \& Riediger, 2003). Although resource gains are possible in later adulthood (e.g., in social status, material belongings, or practical knowledge), the currently prevailing view is that, overall, these resource gains are outweighed by age-associated resource losses (e.g., decreases in physical fitness or health, illness or death of close social partners). In addition, remaining years of life, a central resource for the realization of all future-orientated aspirations, are increasingly perceived as limited (Carstensen et al., 1999). In older adulthood, then, the necessity of regulatory processes that guide the focused investment of resources becomes increasingly magnified. This increased necessity coincides with a decrease in the regulatory scaffolding provided by society. In older adulthood, social expectations are less clear and roles less explicitly defined (Maddox, 1994; Riley, Kahn, \& Fohner, 1994). Heckhausen and Schulz (1999) concluded that individuals themselves have to take on the regulation of aging-related resource losses (see also Wrosch \& Freund, 2001). We therefore expected that the increase in resource limitations, coupled with the decrease in social-structural scaffolding and a potential increase in life experience and life-management competence, should render it both increasingly necessary and increasingly possible in older adulthood to be selective about one's future-oriented aspirations. We therefore expected that older as compared with younger and middle-aged adults are more likely to focus on a restricted number of goals that are similar to each other and that address those life domains that the person regards as highly central for his or her life satisfaction.

There is some evidence that the first facet of motivational selectivity-restricting the number of goals-increases throughout adulthood. For example, Cross and Markus (1991) observed in a cross-sectional sample that adults reported fewer hoped-for and feared possible selves the older they were. A similar finding was

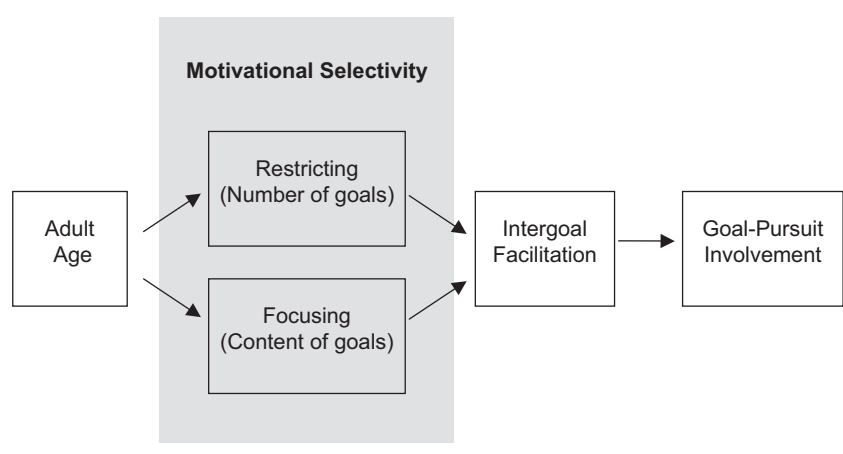

Figure 1. Theoretical working model: illustration of central predictions 
reported by Freund and Baltes (2002), who found in a crosssectional sample that adults' self-reported tendency to engage in elective selection increases throughout adulthood.

There is also some empirical evidence that is consistent with the view that motivational selectivity in terms of focusing on subjectively important life domains might increase in older adulthood. For example, in the domain of social relations, research emanating from socioemotional selectivity theory (Carstensen, 1993, 1998) has shown that the decrease in social network size in later adulthood largely results from a selective pruning process that older adults intentionally initiate in accordance with their priorities in social interactions. Older adults have been found to deliberately discard emotionally less important relationships but to maintain intensive relations to emotionally close interaction partners (e.g., Fung, Carstensen, \& Lang, 2001; Lang, 2000).

The purpose of this study was to investigate the implications of older adults' increased selectivity for their goal-directed behavioral investment. We predicted that motivational selectivity might serve an important behavioral function in older adulthood, namely, the maintenance of high levels of active involvement in goal pursuit, despite age-associated declines in available resources, and that a high extent of intergoal facilitation plays a mediating role in this association.

\section{Overview of the Present Study}

To investigate our predictions, which are summarized in Figure 1, we conducted a short-term longitudinal study with an age-heterogeneous sample covering the adult life span from earlier to later adulthood (20 to 69 years of age). The study comprised two sessions about 3 months apart. Motivational selectivity and intergoal facilitation were assessed at the first session, and involvement in goal pursuit at the second. Although age-related differences could only be tested cross-sectionally, this design allowed testing the propositions of our working model on the function of selectivity for goal pursuit in a prospective manner.

\section{Method \\ Sample}

At the first measurement session, the sample comprised 177 participants ranging in age from 20.10 to 69.43 years $(M=44.69, S D=14.55)$. About equal numbers of participants belonged to each of five age groups (20-29 years, $30-39$ years, $40-49$ years, $50-59$ years, $60-69$ years; see Table 1 ). Within each age group, the sample was approximately stratified by gender (total sample: $47.5 \%$ men and $52.5 \%$ women) and education (total sample, male participants: $48.8 \%$ less than 12 years of education, $51.2 \% 12$ or more years of education; total sample, female participants: $47.3 \%$ less than 12 years of education, $52.7 \% 12$ or more years of education).

A survey company contacted Berlin residents by means of a random dialing procedure and asked for their willingness to participate in this study. Participants were recruited on a first-come basis until prescribed cell sizes of the sample composition were reached. Table 1 gives an overview of the five investigated age groups on sociodemographic characteristics at the first measurement session.

\section{Procedure}

The study procedure comprised two assessment sessions with an average interval of about 3 months $(M=88.2$ days, $S D=10.5)$. At each of these measurement sessions, participants completed a set of questionnaires in small groups. At Time 1 (T1), participants reported their current personal goals and we obtained information on their motivational selectivity and on the extent of mutual facilitation among their goals. At Time 2 (T2), we assessed how intensively participants had engaged in goal-pursuit behaviors during the study interval. Respective instruments are described in the Instruments section. At both measurement sessions, participants completed a number of additional instruments that are not relevant here. Participants received a 15-Euro (approximately \$20) reimbursement for each measurement session.

Table 1

Sociodemographic Sample Characteristics at Time 1

\begin{tabular}{|c|c|c|c|c|c|}
\hline Characteristic & $\begin{array}{l}20-29 \text { years } \\
(n=35)\end{array}$ & $\begin{array}{c}30-39 \text { years } \\
(n=35)\end{array}$ & $\begin{array}{l}\text { 40-49 years } \\
(n=34)\end{array}$ & $\begin{array}{c}50-59 \text { years } \\
(n=39)\end{array}$ & $\begin{array}{c}60-69 \text { years } \\
(n=34)\end{array}$ \\
\hline \multicolumn{6}{|l|}{ Age (in years) } \\
\hline Range & $20.10-29.92$ & $30.03-39.44$ & $40.51-49.77$ & $50.02-59.95$ & $60.07-69.43$ \\
\hline$M$ & 23.50 & 35.64 & 44.80 & 54.17 & 64.84 \\
\hline$S D$ & 2.77 & 2.69 & 2.87 & 2.94 & 2.72 \\
\hline \multicolumn{6}{|l|}{ Gender } \\
\hline Male (\%) & 51.4 & 45.7 & 44.1 & 46.2 & 50.0 \\
\hline Female (\%) & 48.6 & 54.3 & 55.9 & 53.8 & 50.0 \\
\hline \multicolumn{6}{|l|}{ Education } \\
\hline Lower $^{\mathrm{a}}(\%)$ & 42.9 & 51.4 & 41.2 & 51.3 & 52.9 \\
\hline Higher $^{\mathrm{b}}(\%)$ & 57.1 & 48.6 & 58.8 & 48.7 & 47.1 \\
\hline \multicolumn{6}{|l|}{ Current occupation } \\
\hline Working $^{\mathrm{c}}(\%)$ & 20.0 & 48.6 & 53.0 & 46.1 & 8.7 \\
\hline Out of work (\%) & 11.4 & 31.4 & 26.5 & 33.3 & 5.9 \\
\hline Retired $(\%)$ & & & 5.9 & 10.3 & 73.5 \\
\hline Student (\%) & 42.9 & 11.4 & & & \\
\hline Trainee (\%) & 8.6 & & 2.9 & & \\
\hline Homemaker (\%) & & 5.7 & 8.8 & 10.3 & 2.9 \\
\hline Other (\%) & 17.1 & 2.9 & 2.9 & & 8.8 \\
\hline
\end{tabular}

${ }^{\mathrm{a}}$ Lower education $=$ less than 12 years of education. ${ }^{\mathrm{b}}$ Higher education $=12$ or more years of education.

${ }^{\mathrm{c}}$ Working $=$ Full-time, part-time, or self-employed. 
Of the 177 participants at $\mathrm{T} 1,160(90.4 \%)$ also participated at T2 (20-29 years: $n=29,82.9 \% ; 30-39$ years: $n=29,82.9 \% ; 40-49$ years: $n=32,94.1 \%$; 50-59 years: $n=38,97.4 \% ; 60-69$ years: $n=32$, $94.1 \%)$. Participants who only participated at $\mathrm{T} 1 \mathrm{did}$ not differ from those who took part in both measurement occasions in any of the variables that are relevant here and were assessed at T1 (i.e., three facets of motivational selectivity and intergoal facilitation; discussed later).

\section{Instruments}

\section{Personal Goals (T1)}

At T1, participants were asked to describe their current goals in an open response format. They were instructed to report goals that they had for the near future (i.e., coming weeks, months, or years), currently judged to be important, and that they expected would still be important in the coming weeks or months. The instructions included a brief explanation of the concept of goals as well as sample life domains and sample goals. ${ }^{2}$ The number of goals to be reported was not specified. Following this free self-report, participants were asked to select the three goals they considered to be most important out of their list of reported goals. These three goals were then rated on a number of dimensions (as described later in this article). The decision to focus on the participants' three most important goals was based on our expectation from previous research observations that a high percentage of participants would report at least three goals when the number of to-be-reported goals is not specified, whereas a considerably lower percentage would report four or more goals. This expectation was confirmed in the present study: 173 participants (97.7\%) reported at least three goals. More than three goals were reported by 130 participants (73.4\%).

\section{Motivational Selectivity (T1)}

At T1, we assessed two facets of motivational selectivity. One facet pertained to the quantity of reported goals (i.e., restricting to few vs. many goals). The other facet pertained to the quality (or content) of the reported goals (i.e., focusing on similar vs. diverse goals and on central vs. marginal goals).

Selectivity in terms of restricting. We used the number of current goals reported at $\mathrm{T} 1$ as an indicator of the quantity aspect of motivational selectivity. One univariate within-age-group outlier was identified in the oldest subsample $(z$ score $=3.39$, raw score $=10)$ and adjusted to the closest raw value in the within-age-group distribution (raw score $=9$; total sample: $M=5.15, S D=2.08){ }^{3}$

Selectivity in terms of focusing. We assessed two content-related aspects of motivational selectivity, namely, the similarity (vs. variability) and the centrality (vs. marginality) of personal goals reported at T1. Respective indicators were derived with respect to 14 content (life) domains. Previous research has shown that life domains addressed in people's goals vary substantially according to age. On the basis of these findings (e.g., Heckhausen, 1997; Nurmi, 1992), we aimed at compiling a selection of life domains that includes in equal parts domains with high relevance for different adult age groups. Assembling such an "age-fair" selection of life domains was a prerequisite for investigating potential age-associated differences in the two content-related selectivity indicators (see later). Our selection included the following domains: (a) friends-acquaintances, (b) family circle-children, (c) profession-work, (d) health-physical wellbeing, (e) education, (f) recreational activities, (g) financial situation, (h) material belongings, (i) partnership, (j) personal characteristics, (k) mental health, (1) physical capability, (m) enjoyment of life, and (n) appearance.

Three different approaches empirically supported the assumption that the prerequisite of age-fairness in the selection of life domains was met. First, we asked participants to indicate how important they considered each of the 14 life domains to be for their life satisfaction. Response options ranged from 1 (not at all important) to 7 (very important). As expected, participants in the five age groups differed in the subjective importance they ascribed to single life domains. When averaged across all domains, however, the five age groups did not differ significantly with respect to (a) the mean importance they ascribed to the 14 life domains $(M=5.49, S D=$ $.64)$ and (b) the within-person standard deviation of these 14 importance ratings $(M=1.31, S D=.40)$. There also were no age-group differences in (c) the number of life domains participants rated as highly important (i.e., a rating of 6 or $7 ; M=8.17, S D=2.82$ ), as moderately important (i.e., a rating of 3,4 , or $5 ; M=5.27, S D=2.73$ ), or as unimportant for their life satisfaction (i.e., a rating of 1 or $2 ; M=.67, S D=1.09$; all $p \mathrm{~s}>.65$ ). Second, we asked participants to evaluate how relevant each of the 14 life domains was for each of their three most important goals. Response options ranged from 1 (not at all relevant) to 5 (very relevant). The five age groups did not differ with respect to (a) the mean goal relevance they ascribed to these 14 life domains across all three goals (averaged across all life domains and goals; $M=3.43, S D=.50$ ), (b) the overall number of life domains participants rated as highly relevant (i.e., a rating of 4 or 5 ) for at least one of their goals $(M=11.27, S D=1.91)$, and (c) the average number of life domains they rated as highly relevant for each of their three most important goals (averaged across all three goals; $M=7.36, S D=$ 2.05; all $p \mathrm{~s}>.25$ ). Third, using a dichotomous (yes-no) item, we asked participants to indicate, for each of their three most important goals, whether there are life domains other than the 14 included in the list that are relevant for this goal. Again, the five age groups did not differ in the number of participants who affirmed this item for one or more of the three goals $(M=6.80, S D=1,48), \chi^{2}(4, N=175)=1.03, p=.91$.

In short, the empirical basis is strong for assuming that the prerequisite of age fairness in the compilation of life domains was met. This warrants the derivation of the two selectivity indicators described next and the interpretation of respective age-group differences.

First, as an indicator of the extent to which participants were selective in terms of selecting similar (vs. diverse) goals, we determined the variability of the life-domain relevance of the participants' three most important goals (following a rationale used by Sheldon \& Emmons, 1995). As described earlier, participants rated, for each of their three most important personal goals, how relevant this goal was for each of 14 life domains. We first

\footnotetext{
${ }^{1}$ According to Wilks's Lambda, the multivariate main effect of group membership (participation at $\mathrm{T} 1$ only vs. participation at $\mathrm{T} 1$ and $\mathrm{T} 2$ ) was not significant, $F(4,154)=0.41, p=.80\left(\right.$ partial $\left.\eta^{2}=.01\right)$, as was the case for all respective univariate effects $(p s>.26)$. There also was no significant multivariate Group Membership $\times$ Age Group interaction, $F(16,471.115)=1.13, p=.32\left(\right.$ partial $\left.\eta^{2}=.03\right)$. Respective univariate interaction effects were also not significant $(p s>.11)$.

${ }^{2}$ Examples of goals reported by a 64-year-old female participant are (a) "to continue living a quiet life," (b) "to broaden my knowledge," (c) "to engage in social-welfare activities, that is, to look for an opportunity to work with foreign children," (d) "to become more courageous, take sides when injustice occurs."

${ }^{3}$ To avoid distortions of statistical analyses, we tested all variables for univariate within-age-group outliers, which we defined-in accordance with Tabachnick and Fidell (1996)—as cases with $z$ scores in excess of 3.29 (i.e., with $z$ scores at $p \leq .001$ ). Only one univariate outlier was identified and is described in the Method section. To reduce its impact on statistical analyses, we assigned the outlying case a raw score corresponding to the closest nonoutlying value in the within-age-group distribution. This approach is appropriate because there was no indication that the identified case did not belong to the target population. It did not have extreme values on any of the other investigated variables and did not represent a multivariate outlier in the combination of investigated variables (according to Mahalanobis distance at $p<.001$; there were no multivariate within-age-group outliers at all). We also tested for univariate and multivariate outliers in the total sample. There were none.
} 
determined, separately for each of the 14 life domains, the within-person standard deviation of these ratings across the three goals. This information indicates how distinctively (vs. similarly) participants evaluated the relevance of this particular life domain for their three most important goals. Averaging this information across all 14 life domains yielded an indicator of the overall dissimilarity of the participants' three most important goals in terms of their life-domain relevance $(M=1.00, S D=0.31){ }^{4}$

Second, as an indicator of the degree to which participants were selective in terms of selecting central (vs. marginal) goals, we determined the extent to which they addressed with their goals those life domains they regarded as central to their life satisfaction. As described earlier, participants rated on 7-point rating scales how important they considered each of 14 life domains to be to their life satisfaction. Ratings of 6 or 7, the two highest points on the rating scale, indicated that a person regarded this particular life domain as central to his or her life satisfaction. Participants also indicated, on 5-point rating scales, how relevant each of these 14 life domains was for each of their three most important personal goals. Again, ratings of the two highest points on the rating scale, 4 or 5 , indicated that a particular life domain was highly relevant for a given goal. From these ratings, we determined, separately for each of the three reported goals, which percentage of those life domains that the participant considered highly important for his or her life satisfaction (i.e., importance ratings 6 or 7) were addressed by this goal (i.e., goal relevance rating 5 or 6). Averaging this index across the three most important goals yielded an indicator of the average percentage to which a participant's goals addressed those life domains he or she considered to be central to his or her life satisfaction $(M=64.07 \%, S D=18.03) .{ }^{5}$ Consider the following illustrating example: A person rated 8 of the 14 life domains as highly important for her life satisfaction. Of these 8 life domains, she rated 6 domains (75\%) as highly relevant for her first goal, 4 domains $(50 \%)$ as highly relevant for her second goal, and 5 domains $(62.5 \%)$ as highly relevant for her third goal. This person would receive a centrality score of $62.5 \%$, which is the average percentage to which this person's goals addressed those life domains she considered to be central to her life satisfaction.

\section{Intergoal Facilitation (T1)}

To assess the extent of mutual facilitation among the participants' three most important personal goals reported at $\mathrm{T} 1$, participants responded, for each of the 6 pairwise combinations of these goals, to the facilitation scale of the Intergoal Relations Questionnaire (IRQ; Riediger \& Freund, 2004; Riediger et al., 2005). This scale includes, for each pair of goals, two items that assess intergoal facilitation in terms of (a) instrumental goal relations ("The pursuit of goal A sets the stage for the realization of goal B"; response options: $1=$ not at all true, $5=$ very true) and (b) overlapping goal-attainment strategies ("How often can it happen that you do something in pursuit of goal A that is simultaneously beneficial for goal B?"; response options: $1=$ never/very rarely, $5=$ very often). In all, participants responded to 12 items. Averaging these items yielded the facilitation composite $(M=3.06, S D=0.83$, Cronbach's $\alpha=.83){ }^{6}$

\section{Goal Pursuit (T2)}

At T2, participants responded, for each of the three most important goals they had reported at T1, to the following items: "In the past three months since you first participated in this study, on average ... (a) How much have you done for this goal? (b) How much energy have you invested in this goal? (c) How regularly have you worked on this goal? (d) How much time have you invested in this goal? (e) How often have you thought about this goal? (f) How much has this goal determined your everyday life?"

All items used a 7-point response scale. Averaging across all 18 items (all three goals) yielded an indicator of the participants' average intensity of goal pursuit in the study interval $(M=4.85, S D=0.74$, Cronbach's $\alpha=$ $.86)$.

\section{Results}

The description of results is organized as follows. We first present results regarding age-group mean differences in the various measures of motivational selectivity, intergoal facilitation, and intensity of goal pursuit. Then, we present results of structural equation models testing our predictions regarding associations between the study variables in the investigated sample.

\section{Age-Group Mean Differences in Study Variables}

A multivariate analysis of variance on the three indicators of motivational selectivity (assessed at T1), the indicator of intergoal facilitation (assessed at T1), and the indicator of goal-pursuit intensity (assessed at T2) yielded a significant multivariate agegroup effect according to Wilks's Lambda, $F(20,471.911)=2.33$, $p=.001$ (partial $\eta^{2}=.08$ ). Means and standard deviations of each of these constructs in the five investigated age groups as well as results of univariate follow-up analyses are summarized in Table 2. The five age groups did not differ in the self-reported intensity of investment in goal pursuit during the study interval. Consistent with our predictions, however, there were significant univariate age effects on the intergoal facilitation composite and on each of the three motivational selectivity indicators-that is, number of goals, selection of central goals, selection of (dis-)similar goals (see Table 2).

Figure 2 illustrates that univariate age effects in all four of these variables were not linear but were driven by a distinctive pattern of results in the oldest age group (60-69 years of age). (Note that for illustration purposes, number and dissimilarity of goals were recoded prior to depiction in Figure 2 so that higher scores indicate higher selectivity.) Consistent with previous findings (Riediger et al., 2005), participants in the oldest group reported significantly higher levels of intergoal facilitation than did the other age groups. Also consistent with our hypotheses, participants in the oldest age group were significantly more selective in all three measures of motivational selectivity: (a) Participants in the oldest group listed significantly fewer personal goals in free self-report than younger and middle-aged adults. (b) Goals reported by participants in the oldest age group were more similar in content than goals reported by younger and middle-aged adults. That is, older adults' evaluations of how much each of their three most important goals had to do with 14 life domains evinced significantly less variance than the respective life-domain relevance ratings of younger and middleaged participants. (c) Participants in the oldest age group reported more subjectively central goals than did younger and middle-aged adults. That is, their three most important goals were more highly

\footnotetext{
${ }^{4}$ This information was not available for one 69 -year-old female participant ( $0.6 \%$ of the total sample) who provided incomplete responses to goal relevance ratings of life domains.

5 This information was not available for 5 participants $(2.8 \%$ of the total sample: 1 male participant, 34.85 years; 4 female participants, 59.56 , $62.31,64.25$, and 67.89 years, respectively) who rated none of the 14 life domains as highly important for their life satisfaction.

${ }^{6}$ This information was not available for 5 participants $(2.8 \%$ of the total sample: 1 male participant, 35.14 years; 4 female participants, 41.21, 49.31, 52.63, and 62.31 years, respectively) who provided incomplete responses to the IRQ items.
} 
Table 2

Description of Study Variables per Age Group and Univariate Tests of Age-Group Mean Differences (Analyses of Variance)

\begin{tabular}{|c|c|c|c|c|c|c|c|c|c|c|c|c|c|c|}
\hline \multirow[b]{2}{*}{ Construct } & \multicolumn{2}{|c|}{ 20-29 years } & \multicolumn{2}{|c|}{ 30-39 years } & \multicolumn{2}{|c|}{ 40-49 years } & \multicolumn{2}{|c|}{$50-59$ years } & \multicolumn{2}{|c|}{$60-69$ years } & \multirow[b]{2}{*}{$F$} & \multirow[b]{2}{*}{$\eta^{2}$} & \multicolumn{2}{|c|}{ Contrast } \\
\hline & $M$ & $S D$ & $M$ & $S D$ & $M$ & $S D$ & $M$ & $S D$ & $M$ & $S D$ & & & Linear & Quadratic \\
\hline \multicolumn{15}{|c|}{ Time 1: Selectivity I (restricting) } \\
\hline $\begin{array}{l}\text { Number of goals } \\
(d f \mathrm{~s}=4,172)\end{array}$ & 5.29 & 1.93 & 5.71 & 2.15 & 5.35 & 2.12 & 5.26 & 2.24 & 4.12 & 1.63 & $3.02 *$ & .07 & $-0.88 *$ & $-0.77 *$ \\
\hline \multicolumn{15}{|c|}{ Time 1: Selectivity II (focusing) } \\
\hline $\begin{array}{l}\text { Centrality of goals } \\
\quad(d f \mathrm{~s}=4,167)\end{array}$ & 60.57 & 15.6 & 60.61 & 16.9 & 60.60 & 18.5 & 67.70 & 19.0 & 71.20 & 18.1 & $2.65^{*}$ & .06 & $9.0 * *$ & $3.8(n s)$ \\
\hline $\begin{array}{l}\text { Dissimilarity of goals } \\
\quad(d f \mathrm{~s}=4,171)\end{array}$ & 1.10 & .28 & 1.12 & .28 & 1.06 & .28 & .94 & .30 & .77 & .27 & $9.06 * *$ & .18 & $-0.27 * *$ & $-0.12 *$ \\
\hline \multicolumn{15}{|c|}{ Time 1: Facilitation among goals } \\
\hline $\begin{array}{l}\text { Intergoal facilitation } \\
\quad(d f \mathrm{~s}=4,167)\end{array}$ & 2.97 & .93 & 2.87 & .71 & 2.75 & .88 & 3.04 & .71 & 3.68 & .63 & $7.16^{* *}$ & .15 & $0.50 * *$ & $0.51 * *$ \\
\hline \multicolumn{15}{|c|}{ Time 2: Goal-directed action in study interval } \\
\hline $\begin{array}{l}\text { Goal-pursuit intensity } \\
\quad(d f \mathrm{~s}=4,155)\end{array}$ & 4.79 & .77 & 4.89 & .76 & 4.73 & .90 & 4.85 & .68 & 4.98 & .62 & $0.53(n s)$ & .01 & $0.10(n s)$ & $0.10(n s)$ \\
\hline
\end{tabular}

Note. $\quad \eta^{2}=$ partial $\eta^{2} . n s=$ nonsignificant at the $p<.05$ level.

$* p<.05$. ** $p<.01$.

related to those life domains they regarded as highly important for their life satisfaction. ${ }^{7}$ The remaining four age groups of young and middle-aged adults (covering the age range from 20 to 59 years old) were largely comparable in the extent of intergoal facilitation and in the three facets of motivational selectivity (for pairwise tests of mean differences between age groups, see Table 3).

As a first step toward exploring factors underlying the observed pattern of age-group differences, we examined whether these age effects are due to the fact that, in contrast to all other age groups, most of the participants above age 60 were no longer involved in work or study (see Table 1). To investigate this, we derived an indicator of the participants' occupational status using the catego-

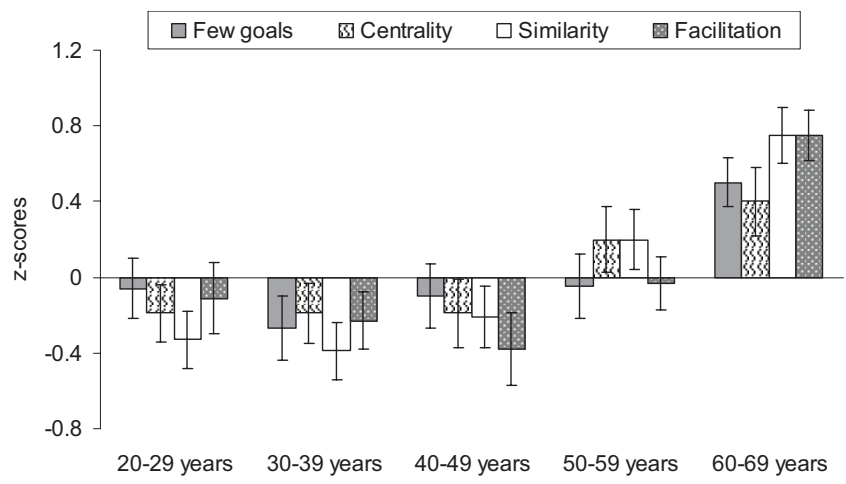

Figure 2. Age-group means of three facets of motivational selectivity and of intergoal facilitation (deviations from grand mean). Error bars represent two standard errors of the mean. ries (a) retired-homemaker, (b) working-studying (i.e., being employed, student, or trainee), (c) unemployed, and (d) other. We then conducted four hierarchical regression analyses with intergoal facilitation and the three motivational selectivity indicators as dependent variables. In a first step, occupational status was entered using dummy-variable coding and the occupational status category "retired/homemaker" as reference group. Unstandardized regression coefficients reflect mean differences in the dependent variable between participants who are retired or homemakers and participants of the other occupational status groups. In second and third steps, age (grand-mean centered) and the respective squared age term were added. (Note that we used age as a continuous, rather than categorical, variable in these and all following analyses.) Results are depicted in Table 4.

In two of the four analyses, occupational status explained significant amounts of variance in the dependent variable: Nonworking persons (i.e., retirees and homemakers) reported significantly fewer goals than both participants who were employed or in training and participants with unspecified occupational status of "other" (7\% of variance explained). In addition, nonworking participants showed significantly less dissimilarity among their goals than all other occupational status categories (10\% of variance

\footnotetext{
${ }^{7}$ Please note that there were no age-related differences in the overall percentage of subjectively central life domains participants addressed with at least one of their goals $(M=91.92, S D=12.70, p=.73)$. What this result indicates is that participants in the oldest age group addressed with each single of their three most important goals, on average, a higher percentage of subjectively central life domains than did younger and middle-aged adults.
} 
Table 3

Follow-Up Analyses of Significant Univariate Age Effects: Significance of Least Significant Difference Pairwise Comparison Tests of Mean Differences Between Age Groups

\begin{tabular}{|c|c|c|c|c|c|}
\hline & & \multirow{3}{*}{$\begin{array}{l}\text { Selectivity I: } \\
\text { No. of goals } \\
p\end{array}$} & \multicolumn{2}{|c|}{ Selectivity II } & \multirow{3}{*}{$\begin{array}{c}\text { Goal system: } \\
\text { Facilitation } \\
p\end{array}$} \\
\hline \multicolumn{2}{|c|}{ Pairwise comparison } & & Centrality & (Dis-)Similarity & \\
\hline Age group & Age group & & $p$ & $p$ & \\
\hline \multirow[t]{4}{*}{$60-69$} & $50-59$ & .018 & $n s$ & .012 & .001 \\
\hline & $40-49$ & .013 & .017 & .000 & .000 \\
\hline & $30-39$ & .001 & .017 & .000 & .000 \\
\hline & $20-29$ & .018 & .016 & .000 & .000 \\
\hline \multirow[t]{3}{*}{$50-59$} & $40-49$ & $n s$ & $n s$ & $n s$ & $n s$ \\
\hline & $30-39$ & $n s$ & $n s$ & .007 & $n s$ \\
\hline & $20-29$ & $n s$ & $n s$ & .016 & $n s$ \\
\hline \multirow[t]{2}{*}{$40-49$} & $30-39$ & $n s$ & $n s$ & $n s$ & $n s$ \\
\hline & $20-29$ & $n s$ & $n s$ & $n s$ & $n s$ \\
\hline $30-39$ & $20-29$ & $n s$ & $n s$ & $n s$ & $n s$ \\
\hline
\end{tabular}

Note. $n s=$ nonsignificant at the $p<.05$ level.

explained). Occupational status did not contribute to the prediction of centrality of goals and of intergoal facilitation.

Of interest, after statistical control of participants' occupational status, the age terms still contributed significantly to the prediction of the two indicators of focusing - that is, (dis-) similarity and centrality of goals - and to the prediction of intergoal facilitation. The age terms did not, however, contribute significantly to the prediction of restricting after controlling for participants' occupational status. That is, age-group differences in occupational status did not account for the observed age-group differences in intergoal facilitation and the two indicators of focusing but might explain why older participants reported fewer goals than all other age groups.

\section{Associations Between Study Variables}

Bivariate correlations between study variables are depicted in Table 5. (Note that number and dissimilarity of goals were recoded so that higher scores indicate higher selectivity.) We tested all of these bivariate associations for interactions with participants' age. None of the age interactions were significant $(p>.21)$. We also investigated whether it is the simultaneous maximization of several facets of motivational selectivity that is associated with adaptive outcomes. This, however, was not the case. Specifically, we tested whether any of the following interactions significantly contributed to the predictions of intergoal facilitation and of goalpursuit intensity: (a) Restricting $\times$ Similarity, (b) Restricting $\times$ Centrality, (c) Similarity $\times$ Centrality, and (d) Restricting $\times$ Similarity $\times$ Centrality. None of these interactions was statistically significant $(p>$.09). In addition, we tested (e) the Restricting $\times$ Similarity $\times$ Centrality $\times$ Facilitation interaction in the prediction of goal-pursuit intensity, which was also not significant $(p=.94)$. All interactions were tested following multiple regression recommendations by Aiken and West (1991).

Using structural equation modeling and Amos 5.0 (Arbuckle, 2003), we conducted a series of analyses to simultaneously investigate our assumptions regarding associations between study variables. Because of few instances of missing data in the present data set (see the Method section), we used the full information maximum-likelihood (FIML) algorithm for the estimation of model parameters (for simulation studies demonstrating the effectiveness of the FIML algorithm in incomplete data sets, see, e.g., Enders \& Bandalos, 2001; Wothke, 2000).

In Model 1 (see Figure 3), we tested the assumptions of our initial working model. According to this model, the two facets of motivational selectivity-restricting (the number of goals) and focusing (the content of goals) — quadratically increase from early to later adulthood and contribute to high intergoal facilitation, which in turn contributes to high behavioral engagement in goal pursuit. Again, we used the number of goals reported at T1 as an (inverse) indicator of restricting, and (dis-)similarity and centrality of goals as indicators of focusing. Number and dissimilarity of goals were recoded so that higher scores indicated higher selectivity. Indicators of intergoal facilitation were the two IRQ subscales: (a) Instrumental Relations Among Goals and (b) Overlapping Goal Attainment Strategies. Indicators of behavioral involvement in goal-pursuit activities, finally, were three 2-item parcels of the goal-pursuit scale participants responded to at T2. These parcels reflected how much (a) energy and (b) time participants had invested, since $\mathrm{T} 1$, into their three most important initially reported goals, and (c) how much these goals had determined their daily life in the study interval. To model the aforementioned finding of nonlinearity in the associations between age and the two facets of motivational selectivity (i.e., the steep increase in motivational selectivity in older adulthood), we included two age indicators: participants' raw age (in years) and the squared term of participants' age. To avoid specifications problems due to linear dependencies among variables, we followed recommendations by T. J. B. Kline and Dunn (2000) and derived the squared term from the grand-mean-centered age distribution. Means, standard deviations, and intercorrelations between all variables in the model are reported in the Appendix.

The overall fit of this model was satisfactory, $\chi^{2}(29, N=$ $175)=48.01, p=.015$; comparative fit index $=.97$; nonnormed fit index $=.94$; incremental fit index $($ Delta 2$)=.97$; root-meansquare error of approximation $=.06(90 \%$ confidence interval $=$ .03 to .09). The model explained between $16 \%$ and $50 \%$ of the 
Table 4

Summary of Hierarchical Regression Analyses for Occupational Status and Age as Predictors of Three Measures of Motivational Selectivity and of Intergoal Facilitation

\begin{tabular}{|c|c|c|c|c|}
\hline Variable & $B$ & $\beta$ & $R^{2}$ & $\Delta R^{2}$ \\
\hline \multicolumn{5}{|c|}{ Dependent variable: Number of goals } \\
\hline \multicolumn{5}{|l|}{ Step 1} \\
\hline Occupational status & & & $.07 * *$ & \\
\hline Retired-homemaker vs. working-studying & 1.24 & $.30 * *$ & & \\
\hline Retired-homemaker vs. unemployed & 0.39 & $.08(n s)$ & & \\
\hline Retired-homemaker vs. other & 1.52 & $.17 *$ & & \\
\hline \multicolumn{5}{|l|}{ Step 2} \\
\hline Age added & & & $.08 * *$ & $.01(n s)$ \\
\hline \multicolumn{5}{|l|}{ Step 3} \\
\hline Age squared added & & & $.10^{* *}$ & $.02(n s)$ \\
\hline
\end{tabular}

Dependent variable: Centrality of goals

Step 1

Occupational status

Retired-homemaker vs. working-studying $\quad-6.25 \quad-.17$ (ns)

Retired-homemaker vs. unemployed $\quad-9.49 \quad-.22 *$

Retired-homemaker vs. other $\quad-2.64 \quad-.04(n s)$

Step 2

Age added $\quad .06 * \quad .03 *$

Step 3

$\begin{array}{lll}\text { Age squared added } & .06(n s) & .00(n s)\end{array}$

Dependent variable: Dissimilarity of goals

Step 1

Vocational status

$\begin{array}{lll}\text { Retired-homemaker vs. working-studying } & 0.22 & .37^{* *} \\ \text { Retired-homemaker vs. unemployed } & 0.22 & .31^{* *}\end{array}$

Retired-homemaker vs. other $\quad 0.22 \quad .17^{*}$

Step 2

Age added $\quad .16^{* *} \quad .06^{* *}$

Step 3

Age squared added

$18 * * \quad .02 *$

Dependent variable: Intergoal facilitation

Step 1

Occupational status

Retired-homemaker vs. working-studying $\quad-0.35 \quad-.21^{*}$

Retired-homemaker vs. unemployed $\quad-0.47 \quad-.23^{*}$

Step 2

Retired-homemaker vs. other $\quad-0.46 \quad-.13(n s)$

$\begin{array}{ll}\text { Age added } & .07 * \\ \end{array}$

\begin{tabular}{l} 
Step 3 \\
Age squared added \\
\hline
\end{tabular}

$* p<.05 . \quad * * p<.01$

variance of the latent constructs (see Figure 3). With one exception, all parameter estimates were significant $(p s<.05)$, and in the hypothesized direction (see Figure 3 and Table 6). The exception involved the path from restricting (the number of goals) to intergoal facilitation. To determine whether the size of this association was in fact negligible, we followed recommendations by Gonzalez and Griffin (2001) and reestimated the model with the path from restricting to facilitation restricted to zero. Imposing this constraint did not significantly impair the overall model fit, $\Delta \chi^{2}(1, N=$ $177)=2.92, p=.09$, which confirmed that the path from restricting to facilitation was not significantly different from zero.
With the aim of specifically addressing the mediational assumptions of our working model, we also tested a model that was identical with Model 1 but in addition allowed direct effects of the two age indicators on intergoal facilitation, and of the two motivational selectivity facets on goal-pursuit intensity. Consistent with our mediational assumptions, the overall fit of this model was not significantly better than that of Model $1: \Delta \chi^{2}(4, N=177)=$ $6.18, p=.19$, and none of the additionally included paths (direct effects) reached statistical significance $(p>.05)$.

We further investigated the hypothesized mediational role of intergoal facilitation by an analysis of the indirect effects of 
Table 5

Intercorrelations Between Study Variables

\begin{tabular}{llclll}
\hline \multicolumn{1}{c}{ Variable } & 1 & 2 & 3 & 4 & 5 \\
\hline 1. Time 1 few goals & - & & & & \\
2. Time 1 centrality of goals & $-.06 n s$ & - & & \\
3. Time 1 similarity of goals & $.06 n s$ & $.57 * *$ & - & \\
4. Time 1 intergoal facilitation & $.19 *$ & $.41^{* *}$ & $.44 * *$ & - & \\
5. Time 2 goal-pursuit intensity & $-.03 n s$ & $.33^{* *}$ & $.26 * *$ & $.34 * *$ & - \\
\hline
\end{tabular}

Note. Number and dissimilarity of goals were recoded so that higher scores indicate higher selectivity. All associations were tested for interactions with age. There were none $(p>.21)$. $n s=$ nonsignificant at the $p<$ .05 level.

$* p<.05$. ** $p<.01$.

restricting and focusing on goal-pursuit intensity in Model 1: According to the modified Sobel test (Baron \& Kenny, 1986; see also R. B. Kline, 1998), and consistent with our assumptions, the indirect effect of focusing (via intergoal facilitation) on goal pursuit intensity at T2 was significant (standardized indirect effect $=$ $.22, p<.001)$. As there was no significant association between restricting and facilitation, however, the indirect effect of restricting (via intergoal facilitation) on goal pursuit intensity was not significantly different from zero (standardized indirect effect $=$ $.14, p=.09$ ).

\section{Summary of Results}

As expected, older participants (60-69 years of age) showed higher motivational selectivity in terms of restricting and focusing than did participants in all other age groups (20-59 years of age). That is, compared with younger and middle-aged adults, older participants reported fewer goals, their goals were more similar to
Table 6

Path Coefficients and Residual Variances in Model 1

\begin{tabular}{|c|c|c|c|}
\hline Model parameter & Estimate $^{\mathrm{a}}$ & $S E$ & $p$ \\
\hline \multicolumn{4}{|l|}{ Path coefficients } \\
\hline Age $\rightarrow$ restricting & 0.03 & 0.01 & .01 \\
\hline Age squared $\rightarrow$ restricting & $<0.01$ & $<0.01$ & .01 \\
\hline Age $\rightarrow$ focusing & 0.35 & 0.08 & $<.001$ \\
\hline Age squared $\rightarrow$ focusing & 0.01 & 0.01 & .02 \\
\hline Restricting $\rightarrow$ facilitation & 0.27 & 0.14 & .06 \\
\hline Focusing $\rightarrow$ facilitation & 0.04 & 0.01 & $<.001$ \\
\hline Facilitation $\rightarrow$ goal pursuit & 0.36 & 0.08 & $<.001$ \\
\hline Few goals $\rightarrow$ restricting & 1.00 & & \\
\hline Central goals $\rightarrow$ focusing & 1.00 & & \\
\hline Similar goals $\rightarrow$ focusing & 0.02 & $<0.01$ & $<.001$ \\
\hline Instrumental $\rightarrow$ facilitation & 1.00 & & \\
\hline Strategies $\rightarrow$ facilitation & 0.77 & 0.09 & $<.001$ \\
\hline Energy $\rightarrow$ goal pursuit & 1.00 & & \\
\hline Time $\rightarrow$ goal pursuit & 0.88 & 0.07 & $<.001$ \\
\hline Daily $\rightarrow$ goal pursuit & 0.79 & 0.07 & $<.001$ \\
\hline \multicolumn{4}{|l|}{ Residual variances } \\
\hline Age & 210.44 & 22.43 & $<.001$ \\
\hline Age squared & $39,468.34$ & $4,207.34$ & $<.001$ \\
\hline Restricting & 1.10 & 0.74 & .14 \\
\hline Focusing & 120.16 & 28.29 & $<.001$ \\
\hline Facilitation & 0.37 & 0.09 & $<.001$ \\
\hline Goal pursuit & 0.52 & 0.07 & $<.001$ \\
\hline Few goals & 2.94 & 0.79 & $<.001$ \\
\hline Central goals & 177.08 & 27.01 & $<.001$ \\
\hline Similar goals & 0.03 & 0.01 & $<.01$ \\
\hline Instrumental & 0.07 & 0.07 & .33 \\
\hline Strategies & 0.39 & 0.06 & $<.001$ \\
\hline Energy & 0.08 & 0.03 & .02 \\
\hline Time & 0.20 & 0.03 & $<.001$ \\
\hline Daily & 0.28 & 0.04 & $<.001$ \\
\hline
\end{tabular}

${ }^{\text {a } U n s t a n d a r d i z e d ~ p a r a m e t e r ~ e s t i m a t e s . ~}$

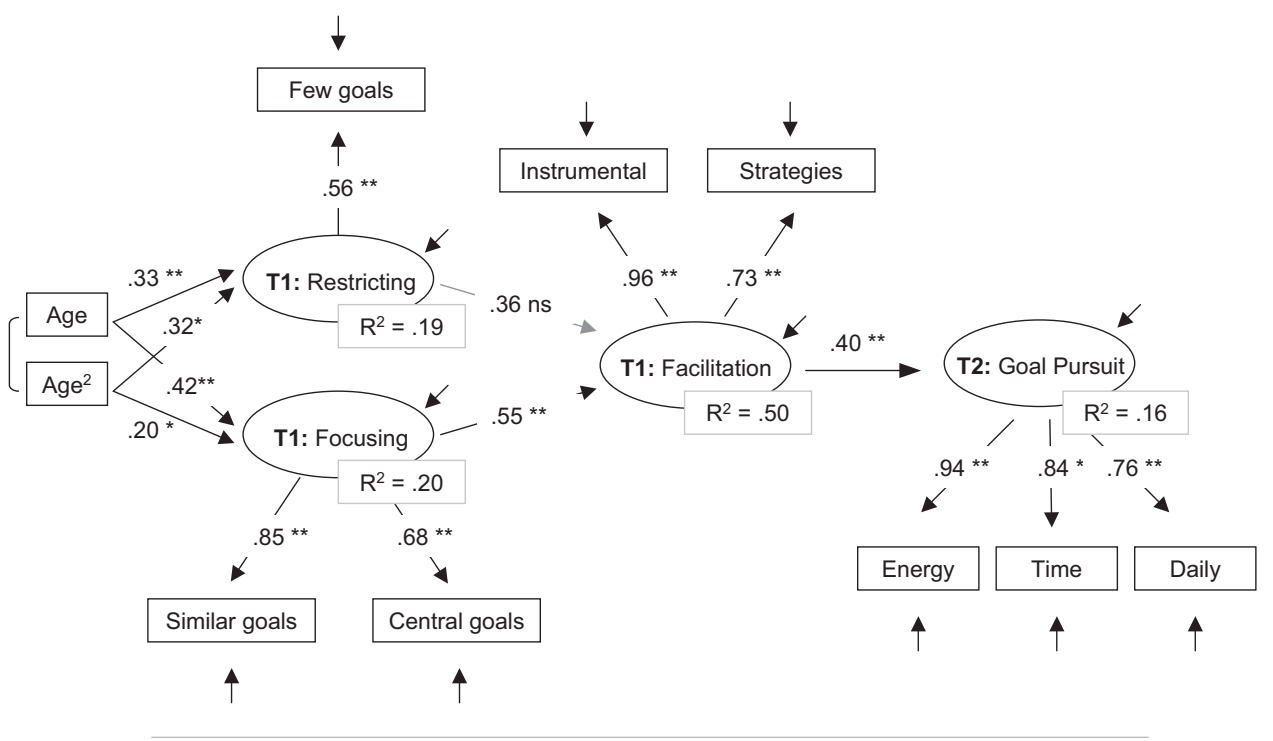

$\chi^{2}(\mathrm{df}=29)=48.01 * . \mathrm{CFI}=.97 . \mathrm{NNFI}=.94 . \mathrm{IFI}($ Delta2 $)=.97$. RMSEA $=.06(90 \% \mathrm{CI}: .03-.09)$

Figure 3. Model 1: parameter estimates (standardized solution) and goodness of fit. CFI = comparative fit index; NNFI = nonnormed fit index; IFI = incremental fit index; RMSEA = root-mean-square error of approximation. $* p<.05, * * p<.01, n s>.05$. 
each other in the life domains they addressed, and these life domains comprised to a larger extent those that the person regarded as highly central for his or her life satisfaction. Consistent with previous research (Riediger et al., 2005), we found that older participants also reported more intergoal facilitation (as indexed by instrumental relations among goals and overlapping goal attainment strategies) than did younger and middle-aged adults. These age effects, with one exception, could not be accounted for by age-group differences in occupational status. The exception involved motivational selectivity in terms of restricting to few goals.

Three months after the assessment of motivational selectivity and intergoal facilitation, the five investigated age groups did not differ from each other in the extent of retrospectively reported behavioral involvement in the pursuit of their initially reported goals, even though the availability of goal-relevant resources is more limited in older than in younger phases of adulthood.

Structural equation modeling demonstrated that relations between study variables were largely consistent with our predictions. With one notable exception, the theoretical model fit the data well. Results confirmed that both facets of motivational selectivityrestricting and focusing-quadratically increased with age. Only motivational selectivity in terms of focusing, however, significantly contributed to high levels of intergoal facilitation, whereas motivational selectivity in terms of restricting did not. In fact, the analyses showed that the higher extent of intergoal facilitation in the oldest age group was completely accounted for by the older adults' higher motivational selectivity in terms of focusing. The analyses further confirmed that high intergoal facilitation contributes, on the behavioral side, to a high involvement in goal pursuit, and that selectivity in terms of focusing was associated with goal-pursuit involvement only via mediation of intergoal facilitation.

\section{Discussion}

Is it better to diversify and have many goals or to focus one's resources on a limited number of options? Under which conditions do people focus with similar goals on central domains of life rather than develop a divergent range of less central alternatives? Results of the present study support the hypothesis that motivational selectivity is an important process of adult developmental regulation. Beginning in the transition from middle to later adulthood, a phase in life when the availability of resources starts to decline and more and more losses are encountered, adults select fewer goals that are more highly related to central life domains and that are more similar in their relevance for life domains. Moreover, focusing (in terms of selecting central and similar goals), but not restricting (the number of goals), contributes to higher facilitation among goals, which, in turn, leads to stronger engagement in goal pursuit. People are more likely to pursue their goals when they focus on central and similar goals. Accordingly, motivational selectivity in terms of focusing appears to be an important process of adapting to changing resources in adulthood.

It is a distinctively human ability to flexibly adjust one's behavior to a vast variety of environmental conditions and demands. From an ontogenetic perspective, this opens a multitude of developmental options, even within the boundaries provided by biological and sociostructural constraints (Heckhausen, 1999). Pursuing developmental options, however, takes resources, such as time, which are only available in restricted quantities (Baltes, 1987, 1998; Carstensen et al., 1999). Current life span developmental theories, such as the SOC model (Baltes \& Baltes, 1990; Freund \& Baltes, 2000), therefore emphasize the importance of focused investment of limited resources into a subset of developmental options.

In the present research, we investigated the expression, adult development, and behavioral function of selectivity as it is evident in people's goals. We distinguished two facets of motivational selectivity, namely, restricting to few goals and focusing on central and similar goals. Our prediction that more selective persons are more involved in the actual pursuit of their goals than are less selective persons was strongly confirmed with respect to motivational selectivity in terms of focusing (the content of goals). That is, the more similar a person's goals are, and the more they pertain to life domains the person regards as highly important for his or her life satisfaction, the more this person will actually engage in behaviors directed at the realization of the selected goals. This association holds independent of a person's age. Motivational selectivity in terms of restricting (the number of goals), however, was unrelated to the intensity of goal pursuit, which was again independent of the individual's age.

This leads to the question of why selectivity in terms of focusing is related to goal-pursuit behavior. Confirming our assumptions, we found that the beneficial effect of focusing on goal-pursuit behavior is mediated through a high extent of mutual facilitation among the participants' goals (as indexed by instrumental relations among these goals and by overlaps in respective goal attainment strategies). In other words, focusing on subjectively central and similar goals results in the tendency for these goals to be mutually facilitative, which, in turn, contributes to a high involvement in goal pursuit. ${ }^{8}$ This finding is consistent with previous studies showing that intergoal facilitation is positively associated with the intensity of goal pursuit (Riediger \& Freund, 2004; Riediger et al., 2005). A possible explanation is that mutual facilitation among goals enhances goal-directed activities by allowing an efficient utilization of one's (limited) resources in the interest of one's goals. Facilitative goals can be pursued simultaneously with little or no additional effort (see Riediger \& Freund, 2004). The present study extends such previous research in an important way. So far, it was unclear which processes and characteristics contribute to mutually facilitative goals systems. Our findings indicate that motivational selectivity in terms of focusing plays a decisive role in this respect.

The present study further demonstrates that the transition from middle to later adulthood-a phase in life when resource limitations start to become increasingly pronounced-is characterized by a substantial increase in motivational selectivity, both in terms of restricting (the number of goals) and in terms of focusing (the

\footnotetext{
${ }^{8}$ Note that the association between intergoal facilitation and goal-pursuit intensity is equally driven by each of the two assessed facets of intergoal facilitation: According to test procedures proposed by Steiger (1980), bivariate associations with goal-pursuit intensity are not significantly different from each other for the two facilitation subscales Instrumental Goal Relations $\left(r_{\text {instrumentality-goal pursuit }}=.33\right)$ and Overlapping Goal Attainment Strategies $\left(r_{\text {overlapping strategies-goal pursuit }}=.30 ; z=0.51, p=.61\right)$. There also were no significant age interactions in these associations $(p>.05)$.
} 
content of goals), and by a sizable increase in the extent of mutual facilitation among goals. There were no systematic age-associated differences in the various facets of motivational selectivity and in intergoal facilitation among the age groups covering the age range from earlier to middle adulthood (i.e., 20 to 59 years of age).

An investigation of the respective role of age-group differences in occupational status indicated, with one exception, that these age-group differences are not attributable to retirement. After controlling for occupational status, age still contributed to the prediction of focusing (on central and similar goals) and of intergoal facilitation. Age did not, however, contribute to the prediction of restricting after controlling for occupational status. That is, whereas changing life circumstances due to retirement might explain why older adults reported fewer goals than did younger and middle-aged adults, they did not account for the fact that older adults select more similar and central goals and report higher intergoal facilitation. Our interpretation is that the reduction in the number of goals in the oldest age group might be a relatively unintentional consequence of the transition to retirement, which implies that work life, hitherto an important goal domain for most people, is no longer relevant for future-oriented aspirations. In contrast, it might be possible that the age effects in focusing and intergoal facilitation reflect older adults' intentional efforts to regulate aging-associated resource losses. These interpretations, however, remain speculative; we could not test them in the present study. We propose that future research would benefit from differentiating intentional (or self-initiated) from unintentional (or opportunistic) forms of motivational selectivity. Both forms of motivational selectivity might have differential functions for adaptive outcomes. On the basis of our findings, for example, we would derive the tentative prediction that it might be particularly selfinitiated (rather than opportunistic) selectivity that contributes to maintenance of high behavioral involvement in goal pursuit. Investigation of the intentionality or automaticity of the observed phenomena thus remains an intriguing quest for future investigations.

The results of the present study are consistent with previous research showing that older adults report higher levels of intergoal facilitation than do younger adults (Riediger et al., 2005). The present study extends the previous research in two respects. First, it does not just compare younger and older adults, as previous studies did, but is the first that investigated an age-heterogeneous sample covering the adult life span from 20 to 69 years of age. Results show that intergoal facilitation does not linearly increase from younger to older adult age groups, but that the increase in intergoal facilitation is specific to the transition from middle to later adulthood. Second, the present research demonstrates that this increase in intergoal facilitation is due to an increase in motivational selectivity in terms of focusing on subjectively central and similar goals, but not to an increase in motivational selectivity in terms of restricting the number of goals. As summarized earlier, mutual facilitation, in turn, contributed to a high involvement in goal-directed action. Accordingly, higher motivational selectivity in terms of focusing appears to have an important behavioral function in a life phase that is characterized by an accelerated increase in aging-associated resource losses (e.g., Baltes, 1987). It allows older adults, despite increasingly pronounced resource limitations, to stay involved in the pursuit of their goals and thus to actively influence the direction of their own development. In fact, the oldest age group was as involved in the pursuit of their goals as were all other age groups. Previous research has even shown that older adults tend to be more involved in goal pursuit than are younger adults (Riediger et al., 2005); this difference, however, did not reach statistical significance in the present sample.

The findings of the present study are based on a short-term longitudinal design. Motivational selectivity in terms of focusing and intergoal facilitation, assessed at $\mathrm{T} 1$, was predictive of the intensity of goal pursuit assessed 3 months later. This supports our interpretation that motivational selectivity in older adulthood ensures the maintenance of high levels of goal pursuit in a reality of increasingly limited resources (e.g., time to live). However, the available information is correlational and therefore does not allow definite conclusions about causality. Another limitation of the present research is that it neither provides information on intraindividual change as people age nor permits modeling of cohort- and age-associated selection effects (Lindenberger, Singer, \& Baltes, 2002). Furthermore, the present sample only covers the age span from 20 to 69 years old. Empirically, it remains open to future research whether the observed findings also apply to very old adults (i.e., the fourth age, Baltes, 1997; Baltes \& Smith, 2003). In addition, the present study relied on self-report in the assessment of goal-pursuit intensity. It remains an interesting task for future studies to investigate whether convergent evidence can be obtained with different methodological approaches (e.g., objective behavioral observations). Finally, although we introduced an expanded heuristic of assessing motivational selectivity, other facets of motivational selectivity might be possible and worthy of empirical investigation from a developmental perspective. Selectivity in terms of focusing, for example, might take other forms than the two content-related aspects of selecting similar and central goals that we investigated in the present study. An example could be selectivity in terms of focusing on those goals for which one has the appropriate resources (e.g., Diener \& Fujita, 1995).

In summary, we propose in this article that selectivity, as reflected in a person's goals, is a multifaceted phenomenon. Previous research has investigated motivational selectivity primarily in terms of restricting to few goals. We posit that another important facet of motivational selectivity is focusing on subjectively central and similar goals. In fact, the present study demonstrates that it is this facet of focusing (rather than that of restricting) that has important behavioral consequences. Focusing is associated with an enhanced involvement in goal-pursuit activities. This association is mediated by the degree of mutual facilitation among the individual's goals. The study further showed that the transition from middle to older adulthood is characterized by a pronounced increase in motivational selectivity (both in terms of restricting and focusing). Older adults select fewer and more similar goals that address subjectively central life domains to a greater extent compared with younger and middle-aged adults. The age-related increase in focusing (selection of similar and central goals), in turn, is reflected in an increase in mutual facilitation among goals, which, as mentioned before, is positively associated with goalpursuit intensity. We conclude that the behavioral function of older adults' pronounced motivational selectivity in terms of focusing is the maintenance of a high level of involvement in goal-pursuit activities, even despite age-associated increases in resource limitations. 


\section{References}

Aiken, L. S., \& West, S. G. (1991). Multiple regression: Testing and interpreting interactions. Newbury Park, CA: Sage.

Arbuckle, J. L. (2003). Amos (Version 5.0) [Computer software]. Chicago: SmallWaters.

Baltes, P. B. (1987). Theoretical propositions of life-span developmental psychology: On the dynamics between growth and decline. Developmental Psychology, 23, 611-626.

Baltes, P. B. (1997). On the incomplete architecture of human ontogeny: Selection, optimization, and compensation as foundation of developmental theory. American Psychologist, 52, 366-380.

Baltes, P. B. (1998). Theoretical propositions of life-span developmental psychology: On the dynamics between growth and decline. In M. P. Lawton \& T. A. Salthouse (Eds.), Essential papers on the psychology of aging: Essential papers in psychoanalysis (pp. 86-123). New York: New York University Press.

Baltes, P. B., \& Baltes, M. M. (1990). Psychological perspectives on successful aging: The model of selective optimization with compensation. In P. B. Baltes \& M. M. Baltes (Eds.), Successful aging: Perspectives from the behavioral sciences (pp. 1-34). New York: Cambridge University Press.

Baltes, P. B., \& Smith, J. (2003). New frontiers in the future of aging: From successful aging of the young old to the dilemmas of the fourth age. Gerontology, 49, 123-135.

Bandura, A. (2001). Social cognitive theory: An agentic perspective. Annual Review of Psychology, 52, 1-26.

Baron, R. M., \& Kenny, D. A. (1986). The moderator-mediator variable distinction in social psychological research: Conceptual, strategic, and statistical considerations. Journal of Personality and Social Psychology, $51,1173-1182$

Carstensen, L. L. (1993). Motivation for social contact across the life span: A theory of socioemotional selectivity. In J. E. Jacobs (Ed.), Nebraska Symposium on Motivation: Vol. 40. Developmental perspectives on motivation (pp. 209-254). Lincoln: University of Nebraska Press.

Carstensen, L. L. (1998). A life-span approach to social motivation. In J. Heckhausen (Ed.), Motivation and self-regulation across the life span (pp. 341-363). New York: Cambridge University Press.

Carstensen, L. L., Isaacowitz, D. M., \& Charles, S. T. (1999). Taking time seriously: A theory of socioemotional selectivity. American Psychologist, 54, 165-181.

Chou, K.-L., \& Chi, I. (2002). Financial strain and life satisfaction in Hong Kong elderly Chinese: Moderating effect of life management strategies including selection, optimization, and compensation. Aging and Mental Health, 6, 172-177.

Cross, S., \& Markus, H. (1991). Possible selves across the life span. Human Development, 34, 230-255.

Diener, E., \& Fujita, F. (1995). Resources, personal strivings, and subjective well-being: A nomothetic and idiographic approach. Journal of Personality and Social Psychology, 68, 926-935.

Emmons, R. A. (1996). Striving and feeling: Personal goals and subjective well-being. In P. M. Gollwitzer \& J. A. Bargh (Eds.), The psychology of action: Linking cognition and motivation to behavior (pp. 313-337). New York: Guilford Press.

Enders, C. K., \& Bandalos, D. L. (2001). The relative performance of full information maximum likelihood estimation for missing data in structural equation models. Structural Equation Modeling, 8, 430-457.

Ford, D. H. (1987). Humans as self-constructing living systems: A developmental perspective on behavior and personality. Hillsdale, NJ: Erlbaum.

Ford, D. H., \& Lerner, R. M. (1992). Developmental systems theory: An integrative approach. London: Sage.

Ford, M. E., \& Ford, D. H. (Eds.). (1987). Humans as self-constructing living systems: Putting the framework to work. Hillsdale, NJ: Erlbaum.
Freund, A. M. (2003). The role of goals for development. Psychologische Rundschau, 54, 233-242.

Freund, A. M., \& Baltes, P. B. (2000). The orchestration of selection, optimization and compensation: An action-theoretical conceptualization of a theory of developmental regulation. In W. J. Perrig \& A. Grob (Eds.), Control of human behavior, mental processes, and consciousness: Essays in honor of the 60th birthday of August Flammer (pp. 35-58). Mahwah, NJ: Erlbaum.

Freund, A. M., \& Baltes, P. B. (2002). Life-management strategies of selection, optimization, and compensation: Measurement by self-report and construct validity. Journal of Personality and Social Psychology, 82, 642-662.

Freund, A. M., \& Riediger, M. (2003). Successful aging. In R. M. Lerner, M. A. Easterbrooks \& J. Mistry (Eds.), Handbook of psychology: Vol. 6. Developmental psychology (pp. 601-628). New York: Wiley.

Fung, H. H., Carstensen, L. L., \& Lang, F. R. (2001). Age-related patterns in social networks among European Americans and African Americans: Implications for socioemotional selectivity across the life span. International Journal of Aging and Human Development, 52, 185-206.

Gonzalez, R., \& Griffin, D. (2001). Testing parameters in structural equation modeling: Every "one" matters. Psychological Methods, 6, 258 269.

Heckhausen, J. (1997). Developmental regulation across adulthood: Primary and secondary control of age-related changes. Developmental Psychology, 33, 176-187.

Heckhausen, J. (1999). Developmental regulation in adulthood: Agenormative and sociostructural constraints as adaptive challenges. New York: Cambridge University Press

Heckhausen, J., \& Schulz, R. (1999). Selectivity in life-span development: Biological and societal canalizations and individuals' developmental goals. In J. Brandtstädter \& R. M. Lerner (Eds.), Action and selfdevelopment: Theory and research through the life span (pp. 67-103). Thousand Oaks, CA: Sage

Kline, R. B. (1998). Principles and practice of structural equation modeling. New York: Guilford Press.

Kline, T. J. B., \& Dunn, B. (2000). Analysis of interaction terms in structural equation models: A non-technical demonstration using the deviation score approach. Canadian Journal of Behavioural Science, 32, $127-132$.

Lang, F. R. (2000). Endings and continuity of social relationships: Maximizing intrinsic benefits within personal networks when feeling near to death? Journal of Social and Personal Relationships, 17, 157-184.

Lindenberger, U., Singer, T., \& Baltes, P. B. (2002). Longitudinal selectivity in aging populations: Separating mortality-associated versus experimental components in the Berlin Aging Study (BASE). Journals of Gerontology, Series B: Psychological Sciences and Social Sciences, 57, P474-P482.

Maddox, G. L. (1994). Lives through the years revisited. Gerontologist, 6 , 764-767.

Neugarten, B. L., Moore, J. W., \& Lowe, J. C. (1965). Age norms, age constraints, and adult socialization. American Journal of Sociology, 70, $710-717$.

Nurmi, J.-E. (1992). Age differences in adult life goals, concerns, and their temporal extension: A life course approach to future-oriented motivation. International Journal of Behavioral Development, 15, 487-508.

Riediger, M. (in press). Interference and facilitation among personal goals: Age-group differences and associations with well-being and behavior. In B. R. Little, K. Salmela-Aro, J.-E. Nurmi, \& S. D. Philipps (Eds.), Personal project pursuit: Goals, action, and human flourishing. Mahwah, NJ: Erlbaum.

Riediger, M., \& Freund, A. M. (2004). Interference and facilitation among personal goals: Differential associations with subjective well-being and persistent goal pursuit. Personality and Social Psychology Bulletin, 30, $1511-1523$ 
Riediger, M., Freund, A. M., \& Baltes, P. B. (2005). Managing life through personal goals: Intergoal facilitation and intensity of goal pursuit in younger and older adulthood. Journals of Gerontology, Series B: Psychological Sciences and Social Sciences, 60, P84-P91.

Riley, M. W., Kahn, R. L., \& Fohner, A. (Eds.). (1994). Age and structural lag: Society's failure to provide meaningful opportunities for work, family, and leisure. New York: Wiley.

Settersten, R. A., Jr., \& Hagestad, G. O. (1996a). What's the latest? Cultural age deadlines for family transitions. The Gerontologist, 36, $178-188$.

Settersten, R. A., Jr., \& Hagestad, G. O. (1996b). What's the latest? II. Cultural age differences for educational and work transitions. The Gerontologist, 36, 602-613.

Sheldon, K. M., \& Emmons, R. A. (1995). Comparing differentiation and integration within personal goal systems. Personality and Individual Differences, 18, 39-46.

Staudinger, U. M., \& Freund, A. M. (1998). Krank und "arm" im hohen Alter und trotzdem guten Mutes? Untersuchungen im Rahmen eines Modells psychologischer Widerstandskraft [Sick and "poor" in old age and still in good spirits? A study of psychological resilience]. Zeitschrift für Klinische Psychologie, Forschung und Praxis, 27, 78-85.

Staudinger, U. M., Freund, A. M., Linden, M., \& Maas, I. (1999). Self, personality, and life regulation: Facets of psychological resilience in old age. In P. B. Baltes \& K. U. Mayer (Eds.), The Berlin Aging Study: Aging from 70 to 100 (pp. 302-328). New York: Cambridge University Press.

Steiger, J. H. (1980). Tests for comparing elements of a correlation matrix. Psychological Bulletin, 87, 245-251.

Tabachnick, B. G., \& Fidell, L. S. (1996). Using multivariate statistics (3rd ed.). New York: HarperCollins.

Wilensky, R. (1983). Planning and understanding. Reading, MA: Addison Wesley.

Wothke, W. (2000). Longitudinal and multigroup modeling with missing data. In T. D. Little, K. U. Schnabel, \& J. Baumert (Eds.), Modeling longitudinal and multilevel data: Practical issues, applied approaches, and specific examples (pp. 219-240, 269-281). Mahwah, NJ: Erlbaum.

Wrosch, C., \& Freund, A. M. (2001). Self-regulation of normative and non-normative developmental challenges. Human Development, 44, $264-283$.

\section{Appendix}

Means, Standard Deviations, and Intercorrelations Between Variables in the Structural Equation Models

\begin{tabular}{|c|c|c|c|c|c|c|c|c|c|c|}
\hline Variable & 1 & 2 & 3 & 4 & 5 & 6 & 7 & 8 & 9 & 10 \\
\hline 1. Time 1 age & - & & & & & & & & & \\
\hline 2. Time 1 age squared ${ }^{a}$ & -.09 & - & & & & & & & & \\
\hline 3. Time 1 restricting: Number of goals ${ }^{\mathrm{b}}$ & -.21 & -.12 & - & & & & & & & \\
\hline 4. Time 1 focusing: Central goals & .20 & .07 & .06 & - & & & & & & \\
\hline 5. Time 1 focusing: Dissimilar goals ${ }^{\mathrm{b}}$ & -.38 & -.14 & .06 & -.57 & - & & & & & \\
\hline 6. Time 1 facilitation: Instrumental & .27 & .23 & -.24 & .42 & -.48 & - & & & & \\
\hline 7. Time 1 facilitation: Strategies & .19 & .23 & -.10 & .33 & -.34 & .70 & - & & & \\
\hline 8. Time 2 goal pursuit: Energy & .13 & .02 & -.03 & .28 & -.28 & .36 & .31 & - & & \\
\hline 9. Time 2 goal pursuit: Time & .08 & .11 & .12 & .33 & -.24 & .30 & .32 & .79 & - & \\
\hline 10. Time 2 goal pursuit: Daily & -.02 & .03 & -.01 & .27 & -.19 & .22 & .17 & .71 & .64 & - \\
\hline$M$ & 44.69 & 210.44 & 5.15 & 64.07 & 1.00 & 3.16 & 2.96 & 4.74 & 4.68 & 5.13 \\
\hline$S D$ & 14.55 & 199.23 & 2.08 & 18.03 & 0.31 & 0.90 & 0.91 & 0.83 & 0.82 & 0.82 \\
\hline
\end{tabular}

${ }^{\mathrm{a}}$ Derived from grand-mean-centered age distribution. $\quad{ }^{\mathrm{b}}$ Associations involving these variables were reflected before reporting in Table 6 and Figure 3.

\section{E-Mail Notification of Your Latest Issue Online!}

Would you like to know when the next issue of your favorite APA journal will be available online? This service is now available to you. Sign up at http://watson.apa.org/ notify/and you will be notified by e-mail when issues of interest to you become available! 